\title{
The trained observer: Effects of prior information on eyewitness reports
}

\author{
GARY THORSON and LARRY HOCHHAUS \\ Oklahoma State University, Stillwater, Oklahoma 74074
}

\begin{abstract}
Sixty subjects from Oklahoma State University viewed a videotape of an automobile accident. Half of the subjects were given prior information concerning (1) the nature of the event they were about to see and (2) the types of questions that would be asked later. The other half of the subjects received no prior information concerning the event or the questions. In addition, subjects were given either a neutral/nonleading questionnaire or a biased/leading questionnaire after viewing the scene. Results indicated that the leading questions led to higher estimates of speed. Prior information did not make the subjects immune to the effects of leading questions on estimates of speed. In addition, informed subjects were more accurate when identifying the types of cars involved.
\end{abstract}

There appear to be two types of information which go into one's memory of a complex occurrence. One is that which is obtained during the perception of the preliminary event, the second is external verbal stimuli added as a result of memory tests, (Loftus \& Palmer, 19.74). Loftus \& Palmer (1974) had subjects view films of complex events and then interrogated them about events which occurred in the films. The question "About how fast were the cars going when they smashed into each other?" brought about higher estimates of speed than did questions using milder verbs, such as "bumped" or "hit," in place of "smashed." A week later the same subjects were re-interrogated. Over time, details became harder to accurately report when leading questions were used. This implies that visual information and verbal information can be combined such that verbal factors may influence visual memories.

Further examples of how the wording of a question can influence answers have been reported by Loftus (1975) and Loftus and Zanni (1975). Subjects viewed a film and were then asked about events that did or did not occur in the film. For some of the questions the definite article "the" was used, as in the question, "Did you see the broken headlight?" Other questions used the indefinite article "a," as in "Did you see a broken headlight?" It was found that subjects interrogated with the article "a" were twice as likely to respond "I don't know."

In another study, Loftus (1974) reported that eyewitnesses were inaccurate in estimating not only speed but also time and distance. Yet, witnesses are frequently called upon to give judgments concerning these aspects. Leading questions play a role in many cases and may have a subtle impact on the outcome of a court case.

Requests for reprints should be sent to Gary Thorson, now at the Department of Psychology, Kearney State College, Kearney, Nebraska 68847.
Buckout (1975) investigated the ability of students to identify an assailant from a group of six photographs. A staged attack on a college professor was witnessed by 141 students; 7 weeks later, students were asked to identify the assailant. Sixty percent of the witnesses chose the wrong man, including the professor who had been attacked; $25 \%$ chose a man who had been at the scene as an innocent bystander. This study further suggested that recognition memory may be poor for complex events and raised the question of even admitting as this type of report as evidence in court.

In many court situations a police officer may be testifying as an eyewitness. His report is often referred to as the testimony of a trained observer. The basic notion seems to be that a trained observer can give more accurate eyewitness reports than the layman. This idea is somewhat questionable and has not been investigated empirically.

The purpose of the present study was to investigate two aspects concerning the ineptness of eyewitnesses. First, it was hypothesized that one could increase the accuracy of eyewitness reports by providing the observers with certain relevant information prior to the event. Second, it was hypothesized that the trained/ informed subjects would be less affected by leading questions than would untrained/uninformed subjects viewing the same scene.

\section{METHOD}

\section{Subjects}

Sixty undergraduate introductory psychology students from Oklahoma State University received extra credit for participation. All subjects reported normal or corrected-to-normal vision.

\section{Apparatus}

A Sony videotape player and a 23 -in. Sony monitor were used to display an 8-sec scene of two cars during an intersection accident. 
Design

A 2 by 2 between-subjects design was used. There were two levels of training (informed and uninformed) and two types of questionnaires (leading and neutral). Fifteen subjects participated in each of the four treatment combinations, for a total of 60 subjects.

\section{Procedure}

Subjects were run in groups of two to four subjects per session. Subjects in the untrained/uninformed condition were told, "You are about to see a videotape of an 8-sec event. Watch carefully." Subjects in the trained/informed condition were told, "You are about to see an 8-sec scene of an automobile accident. After you view the tape we are going to ask you certain questions about the event. First, what kind of cars were involved? Second, how many people were in each car? Third, how fast was each of the two cars going? Fourth, which car was at fault? Now would you repeat the four questions?" If the subjects did not remember all of the questions, they were restated until the subject could remember all four questions.

The subjects were given a ready signal and the tape was played. They were then given a crossword puzzle to work on and instructed not to talk to each other. After $10 \mathrm{~min}$ the subjects were given one of two forms of the questionnaire.

\section{RESULTS}

For the question concerning the speed of the two cars, the analysis of variance revealed a significant main effect of training $[F(1,56)=49.18, p<.001]$, and of type of questionnaire $[F(1,56)=13.58, p<.001]$. The Training by Type of Questionnaire interaction did not reach significance at the .05 level $[F(1,56)=1.69]$. Subjects in the neutral-questionnaire/uninformed condition underestimated the actual speed of the cars, while subjects in the leading questionnaire/informed condition overestimated their speed. Subjects in the neutralquestionnaire/informed condition and subjects in the

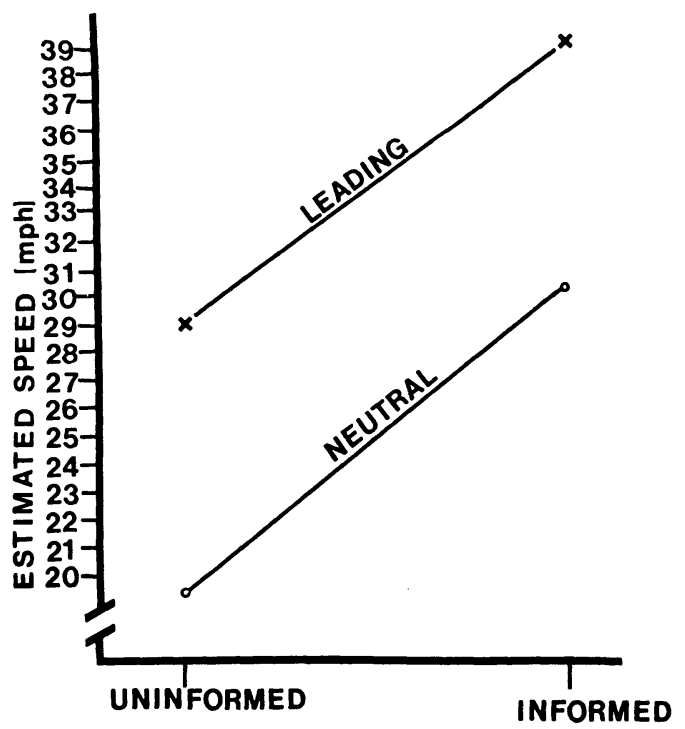

Figure 1. Estimated speed as a function of the four treatment combinations. leading-questionnaire/uninformed condition gave accurate estimates of speed (see Figure 1).

In addition, a greater proportion of subjects in the informed condition than in the uninformed condition identified the cars correctly $\left[\mathrm{X}^{2}(1)=18.84, \mathrm{p}<.0001\right]$. A correlational analysis between accuracy of speed and accuracy of automobile identification revealed a positive but nonsignificant correlation $[\mathrm{r}(58 \mathrm{df})=+.18, \mathrm{p}>.05]$.

\section{DISCUSSION}

Several aspects of the results deserve some further consideration. The finding that leading questions do increase estimates of speed is not totally consistent with the results of Loftus and Palmer (1974). In that study it was found that subjects (given neutral questions) were overestimating the speed of the $30-\mathrm{mph}$ accident by $6.2 \mathrm{mph}$. In the present study subjects who were given nonleading questionnaires underestimated the actual 30 mph speed by $10 \mathrm{mph}$.

There are several possible reasons for this inconsistency between the two studies. First, Loftus and Palmer (1974) used color films projected on a large screen. The present study used a black and white videotape shown on a 23 -in. television monitor. In addition to possible differences in the overall size of the two displays, the accident used in the present study was filmed in a large parking-lot area. This environment provided a minimum of background cues that might have helped the subjects more accurately estimate speed. In the Loftus and Palmer (1974) study, more of these cues may have been present. However, the general finding that subjects are poor at estimating speed is consistent with previous results (Loftus, 1974; Loftus and Palmer, 1974).

Next, the relationship of training and accuracy of speed estimates was examined. The results of the present study showed an increase in the magnitude of speed estimates as a result of training. In addition, there was no significant interaction between training and type of question. This would be consistent with the Loftus and Palmer (1974) conceptualization that there are two components affecting the memory of a complex event. That is, while the effect of training and the effect of leading questions are of the same magnitude here, they appear to represent two different phenomena. One could then interpret the present results to indicate that the process of training affects the information processed during the original perception of the event, while leading questions operate as external information that is integrated with the original perception to produce a bias in memory.

The above interpretation receives further support from subjects' data in the informed/leading-questionnaire condition. In this condition it was originally hypothesized that (1) training would increase the accuracy of the speed estimates and (2) the increase in perceptual accuracy would decrease the effect of biasing or leading questions. According to Loftus and Palmer (1974), it should be possible to increase perceptual accuracy without reducing the effect of leading questions. This appears to be what was observed in the informed/leading-question condition. It is possible that the training increased the speed estimates to accuracy, then the leading questions further increased the estimates by biasing the memory representation, providing an overestimate of almost $9 \mathrm{mph}$.

While the training procedure in the present study consisted of nothing more than informing the subjects of the questions to be later asked, this did affect estimates of speed and accuracy of automobile identification. The correlational analysis of speed accuracy and automobile identification accuracy showed little relationship between performance of the two tasks. In practical terms, it would be possible for a person to give an accurate 
description of a car and a totally inaccurate estimate of speed, or vice versa. In addition, the present study indicates that a person trained to give an accurate estimate of speed may be a very poor witness when faced with a leading question.

\section{REFERENCES}

Buckout, R., Figueroa, D., \& Hoff, E. Eyewitness identification: Effects of suggestions and bias in identification from photographs. Bulletin of the Psychonomic Society, 1975, 6. 71-74.

Loftus. E. F. Reconstructing memory: The incredible eyewitness. Psychology Today, 1974, 8, 116-119.
Loftus, E. F. Leading questions and the eyewitness report. Cognitive Psychology, 1975, 7, 560-572.

LofTus. E. F.. \& PALMer, J. C. Reconstruction of automobile destruction: An example of the interaction between language and memory. Journal of Verbal Learning and Verbal Behavior, 1974, 13, 585-589.

LofTUS. E. F., \& ZANNI, G. Eyewitness testimony: The influence of the wording of a question. Bulletin of the Psychonomic Society, $1975,5,86-88$.

(Received for publication August 8, 1977.) 